\title{
Spatial analysis of indicators affecting the exploitation of shallow geothermal energy at European scale
}

\author{
Adela Ramos-Escudero ${ }^{a,}{ }^{*}$, M. Socorro García-Cascales a , Jose M. Cuevas ${ }^{\text {b }}$, \\ Burkhard Sanner $^{c}$, Javier F. Urchueguía ${ }^{b}$ \\ ${ }^{a}$ Department of Electronics, Computer Architecture and Projects Engineering, Universidad Politécnica de Cartagena, C/Doctor Fleming s/n, Spain \\ ${ }^{\mathrm{b}}$ Information and Communication Technologies vs Climate Change Research Group, Institute for Information and Communication Technologies, Universitat \\ Politècnica de València, Camino de Vera S/N, Spain \\ ${ }^{c}$ UbeG GbR, Reinbergstrasse 2, 35580, Wetzlar, Germany
}

\section{A R T I C L E I N F O}

\section{Article history:}

Received 19 May 2020

Received in revised form

10 November 2020

Accepted 15 November 2020

Available online $\mathrm{xxx}$

\section{Keywords:}

Renewable heating and cooling GIS

Multi-criteria decision-making

Continental scale

\begin{abstract}
A B S T R A C T
Shallow Geothermal Energy (SGE) exploited by vertical close loop Ground Source Heat Pumps (GSHP) is a proven, reliable, and widespread renewable heating and cooling technology. However, in many regions there is still a lack of awareness among policy makers and end users, constituting a major constraint to wider deployment of SGE. In order to contribute to its market consolidation, this work focuses on bringing to light relevant spatial information affecting the suitability of SGE exploitation. This information is the result of the systematization of geological, climatic, and environmental open and available data translated into performance indicators. A set of thematic maps was created using Geographic Information Systems (GIS) comprising the European Member States and other European countries. The relative area and the amount of population affected per indicator was spatially analyzed to determine the most common values found and the affected population. The relationship between area percentage and population affected percentage per indicator was also analyzed and allowed to identify the most common indicators values in areas where high energy demands are expected. Additionally, an example of how this data can be used into a Multi-Criteria Decision-Making (MCDM) framework is shown.
\end{abstract}

(c) 2020 Elsevier Ltd. All rights reserved.

\section{Introduction}

Member States of the European Union (EU) committed to keep temperature increase below $2{ }^{\circ} \mathrm{C}$, and in order to do so pledged to reduce Greenhouse Gas (GHG) emissions by $20 \%$ below 1990 levels [1] by 2020 , and by $80-95 \%$ by 2050 [2]. Although EU GHG emissions had been reduced by $23 \%$ by 2018 , while the economy grew by $61 \%$ over the same period [3], there is still a lot to do. Nowadays, the building sector is the largest energy consumer in Europe which is responsible for $40 \%$ of the energy consumption and $36 \%$ of $\mathrm{CO} 2$ emissions [4]. Within the building sector, heating and hot water account for $79 \%$ of total final energy use, and cooling, although it currently represents a small share of the total final energy use, has a rising demand linked to climate change and increases in temperature [5]. All in all, the housing sector is considered to be key in the reduction of global GHG emissions with a strong saving potential up to $90 \%$ by 2050 [6]. The use of renewable energy sources to reduce GHG are considered inherent to achieve the targets [7]. For this reason, over the last years, an increased focus has been set on the Shallow Geothermal Energy (SGE) exploited by Ground Source Heat Pumps (GSHP) [8] to move forward the decarbonization of the residential sector.

European policies strongly support the deployment of renewable heating and cooling and hold great expectations for SGE. Also, the new Horizon Europe framework program from 2021 to 2027 will have a strong focus on climate change mitigation where SGE will factor in with an important role. Furthermore, nineteen of the European countries have adopted one or more categories of geothermal energy into their National Renewable Energy Action (NREAP) with an overall predicted increase of $83 \%$ in the heat produced by GSHP from 2012 to 2020 [9].

Yet, despite its potential, nowadays only around $2 \%$ of renewable

\footnotetext{
* Corresponding author. Department of Electronics, Computer Architecture and Projects Engineering, Universidad Politécnica de Cartagena, C/Doctor Fleming s/n, Spain. E-mail address: adela.ramos@edu.upct.es (A. Ramos-Escudero).
} 
heating in Europe is produced by these systems [10] and the present rates of growth in Europe are heterogeneous and surprisingly low. Rather than technical issues, non-technological barriers hinder better inclusion of SGE in the heating and cooling market, such as legal barriers, upfront costs, low awareness and visibility for decision makers and end users [11-17]. Many actions are needed to face these issues, and, amongst other measures, regional and national authorities need to invest specifically in information campaigns to raise awareness among stakeholders and decision makers [6,12,13,15,18-21].

In this regard, many studies and projects have assessed indicators affecting GSHP efficiency in general and shallow geothermal energy potential in particular. Computational procedures [22] and numerical models and simulations have been developed by different authors [23-27] to allow simulation and design of systems. But to allow an overall assessment, the question about the site-specific potential of the technology is critical, where climatic, building type and underground site-specific information become key when it comes to assessing SGE potential [25,28,29]. Regarding policy decisions, additional local variables must be taken into account, such as environmental benefits or closeness to the resource to be exploited, among others. In this context, Geographical Information Systems (GIS) are presented as the best tool to overcome the difficulty in combining all this information appropriately to deal with the heterogeneity of the data. They allow not only to store, process and layer the information, but also to illustrate, analyze and draw conclusions from the data. For integrated energy planning and estimation of SGE potentials, the spatial mapping of the availability of energy resources is required [30] and many authors have considered that this information also must be open-access and be published online in GIS viewers [31-34] aimed at being used as a multi-criteria planning tool for decision makers and stakeholders.

Yet, so far, methodologies assessing spatial SGE suitability or/ and SGE potential developed in Europe cover a broad variety of scales, from small areas (plots to cities) $[23,26,35]$ to larger ones (from regions to countries) [24,36]. Very little literature covers continental areas [29,37] whilst most studies are focused on a regional scale.

The objective of this study is to perform a Pan-European spatial assessment of the physical environmental indicators that determine the performance of shallow geothermal energy systems. Several indicators were included, related to (i) geology, (ii) climate, and (iii) environmental protection. The methods used are based on Geographical Information Systems (GIS) and the results consist of a series of thematic maps. From these maps, statistics were extracted to understand what the most common values and their relative frequency in terms of area and population are. Also, areas can be identified where the environmental factors are favorable for the exploitation of this energy source, in order to contrast these with its current implementation level. By making relevant spatial data available among the European countries, energy policies can be better targeted to those areas where this energy source has potential and can thus lead to the promotion of SGE.

The paper is structured as follows: Section 2 describes the research methodology and data used in the study, Section 3 presents the results and Section 4 provides the conclusions.

\section{Data and methodology}

\subsection{Approach}

To assess the suitability for SGE development across Europe, a GIS-based assessment was performed. The analysis focuses on the principal factors that enable or limit the potential for SGE development. These are: (i) geology, (ii) climate, (iii) environmental protection. A large number of input datasets were gathered for this purpose and translated using GIS techniques in spatial datasets that characterize SGE suitability. Table 1 shows for each of the three basic factors the input datasets that were used and the dataset that was derived that is related to the suitability. Table 2 shows the study area characteristics.

Three categories of datasets are considered here as the most relevant for determining the suitability of Shallow Geothermal Energy (SGE) installations at continental scale: first, the geological setting which determines the ground characteristics; second, the climatic conditions playing a role in the energy demand for $\mathrm{H} \& \mathrm{C}$ together with the characteristics of the buildings; and finally, the environmental indicators that could be relevant for the permitting procedure. According to these categories, the selection and collection of relevant spatial data and the processing of raw data, together with the conversion to GIS format and the calculations of the spatial information indicators layers, are identified as the valid approach or method in the study.

\subsection{Study area}

The study area covers the European Member States and other European countries. These are the 27 EU Member States and Albania, Iceland, Liechtenstein, Macedonia, Montenegro, Norway, Serbia, Switzerland, and United Kingdom. Most of the produced thematic maps cover the entire totality of the study area. However, some maps do not cover the whole study area since available data are no accurate enough, or there was no open access information available at all.

\subsection{Data used}

\subsubsection{Geological information}

The main source of geological and hydrogeological data is the European Geological Data Infrastructure (EGDI). The information is part of the International Hydrogeological Map of Europe $1: 1.500 .000$ (IHME1500) [38] and is openly available on the web: (http://www.europe-geology.eu/). The EGDI map offers different lithological groups at five aggregation levels following a hierarchical structure. For this study, all the aggregation levels were used.

- The first aggregation level (Litho 1) is the most detailed one with a uniform lithological taxonomy scheme and encompasses 229 classes of lithological descriptions.

- The second aggregation level (Litho 2) is a generalization of the most detailed level (Litho 1) and comprises only primary and secondary consolidated and/or unconsolidated lithological components in 85 classes (e.g. quartzites, sandstones).

- The third level (Lihto 3 ) is a generalization of Litho 2 and only primary consolidated and/or unconsolidated lithological components are attributed, encompassing 29 lithological classes (e.g. quartzites).

- The fourth level (Litho 4) is an aggregation forming 10 petrographic "supergroups"

- The fifth level (Litho 5) is the most basic group and provides a class division referring to the degree or rock consolidation, thus a distinction of unconsolidated, partly consolidated, and consolidated rocks.

Apart from the previously described, the EGDI map also offers aquifer type information defined in six generalized classes of potential groundwater resources considering four grades of productivity in terms of general groundwater yield. Additionally, highly, or low-to-moderately productive aquifer types are distinguished 
Table 1

Datasets used and reasoning for the approach.

\begin{tabular}{|c|c|c|c|c|}
\hline Factors & Indicators & Based on & Reasoning & Data Sources \\
\hline \multirow[t]{2}{*}{$\begin{array}{r}\text { Geological } \\
\text { settings }\end{array}$} & $\begin{array}{l}1 \text { Thermal } \\
\text { Conductivity }\end{array}$ & $\begin{array}{l}\text { Lithology and } \\
\text { literature values }\end{array}$ & Determine the ground potential to exchange heat with BHE & $\begin{array}{l}\text { European Geological Data Infrastructure (EGDI) } \\
\text { and VDI4640 }\end{array}$ \\
\hline & $\begin{array}{l}2 \text { Material } \\
\text { Consolidation } \\
\text { Grade }\end{array}$ & Lithology & $\begin{array}{l}\text { Ground conditions determine drilling techniques and its } \\
\text { costs associated and hydrogeological aquifer properties }\end{array}$ & EGDI and European Drillability Mapping \\
\hline \multirow[t]{3}{*}{ Climate } & $\begin{array}{l}3 \text { Ground Surface } \\
\text { Temperature }\end{array}$ & $\begin{array}{l}\text { Aire Surface } \\
\text { Temperature at } \\
\text { ground Surface }\end{array}$ & $\begin{array}{l}\text { Determine the basis of temperature of extraction of the } \\
\text { fluids. }\end{array}$ & $\begin{array}{l}\text { Worldclim and U.S. Geological Survey's Center for } \\
\text { Earth Resources Observation and Science (EROS) }\end{array}$ \\
\hline & $4 \mathrm{HDD}+\mathrm{CDD}$ & $\begin{array}{l}\text { Heating and cooling } \\
\text { degree days }\end{array}$ & $\begin{array}{l}\text { The sum of heating and cooling degree days determine } \\
\text { total energy needs of a household. }\end{array}$ & EUROSTAT \\
\hline & $\begin{array}{l}5 \text { Annual } \\
\text { temperature } \\
\text { amplitude }\end{array}$ & $\begin{array}{l}\text { Aire Surface } \\
\text { Temperature and } \\
\text { altitude }\end{array}$ & $\begin{array}{l}\text { Determine how efficient is GSHP compared to a } \\
\text { conventional Air heat Pump. }\end{array}$ & Worldclim \\
\hline Environmental & 6 Protected areas & $\begin{array}{l}\text { Nature and water } \\
\text { protected areas }\end{array}$ & $\begin{array}{l}\text { Determine Water and Nature protected areas where } \\
\text { exploitation of SGE may be restricted. }\end{array}$ & $\begin{array}{l}\text { European Environmental Agency (EEA) and The } \\
\text { International Union for Conservation of Nature } \\
\text { (IUCN) }\end{array}$ \\
\hline
\end{tabular}

Table 2

Study area characteristics.

\begin{tabular}{|c|c|c|c|}
\hline Number of countries within the European Union & Number of other countries in Europe & Total Area $\left(\mathrm{Km}^{2}\right)$ & Total population (people) \\
\hline 27 & 9 & $\approx 5000$ million & $\approx 500$ million \\
\hline
\end{tabular}

based on form by porous or fissured rock types. For this survey, all the types were used.

\section{Porous, less frequently fissured-porous rocks}

a. Highly productive aquifers

b. Low to moderately productive aquifers.

II. Fissured rocks, including karstified rocks, less frequently porous-fissured

a. Highly productive aquifers

b. Low to moderately productive aquifers.

III. Locally aquiferous or practically non-aquiferous, porous or fissured

a. Locally aquiferous, porous of fissured rocks

b. Practically non-aquiferous rocks.

The European Drillability Mapping for shallow geothermal applications [39] provides an assessment of the most accurate drilling technique based on the local stratigraphy (state of consolidation) and the local hydrological conditions which is also based on EDGI. It establishes 6 different drilling techniques based on Litho 1:

- Down-hole hammer without casing

- Down-hole hammer with casing

- Tricone with casing

- Tricone without casing

- Chevron with casing

- Chevron without casing

The latter two, tricone and chevron, refer to rotary drilling with different types of drill bits.

These datasets were used and analyzed in the subsequent spatial analysis of thermal conductivity and Materials consolidation properties.

\subsubsection{Climatic data}

Two main sources of climatic data were used in this work:
WorldClim V.2 [40] for Surface Air Temperature and The Statistical Office of the European Union (EUROSTAT) for heating and cooling degree days [41]. WorldClim V.2 provides a database with minimum, maximum, and average monthly temperature and precipitation data from 1970 to 2000. Information (openly available here: http://worldclim.org/version2) is provided in spatial resolution from approximately $1 \mathrm{~km}^{2}$ (30 arc-seconds longitude/latitude degree) to approximately $340 \mathrm{Km}^{2}$ (10 arc-minutes longitude/latitude degree). For the calculation of ground surface temperature, mean annual temperature data were used with a spatial resolution of 2.5 arcminutes $\left(\sim 3.6 \mathrm{Km}^{2}\right)$. The calculation of the annual thermal amplitude is obtained from the maximum and minimum temperature dataset.

Furthermore, the Statistical Office of the European Union (EUROSTAT) offers annual data of heating and cooling degree days (HDD and CDD) [42] calculated as the sum of monthly basis data from 1975 to 2018 with outdoor temperature and average room temperature of $15^{\circ}$ and $18{ }^{\circ} \mathrm{C}$ respectively for HDD and $24^{\circ}$ and $21^{\circ}$ for CDD as a basis. Data are provided in different Nomenclature of Territorial Units for Statistics (NUTS) levels, from NUTS 0 (national level) to NUTS 3 (provinces/regions level). HDD and CDD 2018 data at NUTS3 level was in this study considered as the most suitable for the spatial analysis.

A Digital Elevation Model (DEM) [43] dataset was also used in supporting and correcting the calculation of Ground surface temperature values affected by altitude. This dataset was provided by U.S. Geological Survey's Center for Earth Resources Observation and Science (EROS) with the only data resolution of approximately $1 \mathrm{~km}^{2}$ spatial resolution (30 arcsecond latitude and longitude) and is openly available at https://databasin.org/datasets/7a286ca8a7fa492a9f95d 58324ca918c.

\subsubsection{Environment}

Spatial environmental data were obtained from two sources: The European Environment Agency (EEA) [44] and The International Union for Conservation of Nature (IUCN). EEA provide a spatial information inventory of national designated protected areas (CDDA), including natural and cultural areas, among the EU countries. This information is classified in two different groups: protected areas classification based on national legislation that 
Table 3

Translation of EDGI geological data in VDI geological classification.

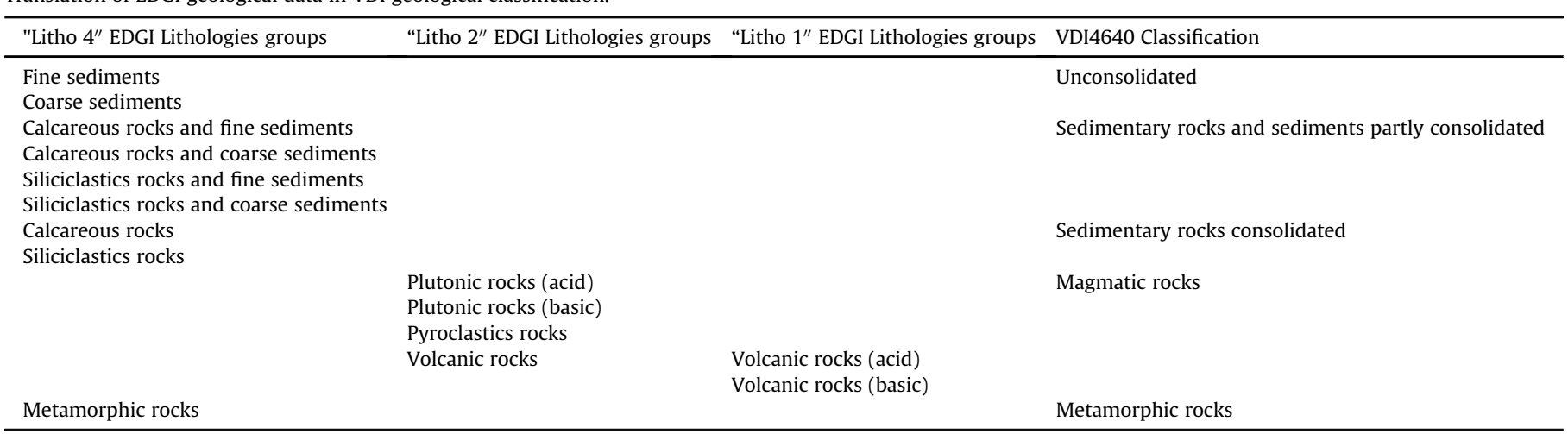

encompasses 275 different European protection groups and a classification provided by IUCN Guideline [45] based on the differences in management approaches. The latter summarizes the 275 groups into six large groups: Ia Strict nature reserve, Ib Wilderness area, II National Park, III Natural monument or feature, IV Habitat/species management area, V Protected landscape or seascape and VI Protected areas with sustainable use of natural resource.

\subsubsection{Population data}

Population data were obtained from The Socioeconomic Data and Applications Center (SEDAC) [46]. This database provides a time series of raster data on Population Density for all over the world, with a 2.5 arcminutes longitude/latitude degree $\left(\sim 3.6 \mathrm{Km}^{2}\right)$ data resolution.

When different resolution data were available, 2.5 arcminute longitude/latitude degree $\left(\sim 3.6 \mathrm{Km}^{2}\right)$ were always selected. Nevertheless, some other data used (DEM) possess higher resolution and resolution lower than 2.5 were never used. When overlapping spatial information data with different resolution, a resample to the lower resolution is done in the output map. In this work, consequently, we obtained final output rasters with 2.5 arcminutes data resolution.

\subsection{Data processing}

\subsubsection{Indicators derived from geological datasets}

2.4.1.1. Systematization of geological data. To be able to link geological data with thermal conductivity and rock consolidation concepts, a previous systematization of the geological data was needed. For this purpose, it was necessary to reduce the number of classifications and to focus on certain key properties.
As a basis for the assignment of thermal conductivity values to the 229 individual lithologies provided, EDGI lithologies were reclassified based on different aggregation levels as depicted in Table 3. Most lithology classes of the European dataset were consistent with the classes of the VDI 4640 table [47]. Very few classes had to be reclassified to the most similar lithological class. After this harmonization exercise, a mean value for thermal conductivity could be assigned to the different lithologies.

As a basis for the assignment of drilling properties classes to the individual lithologies, EDGI Litho 5 was used to provide a division to the degree rock consolidation (consolidated, partly consolidated, and unconsolidated). Additionally, EDGI aquifer type classification was also used and displayed in a different layer to complement the drilling properties survey.

2.4.1.2. Thermal conductivity. Thermal conductivity is a key indicator as it determines the SGE efficiency of the heat transfer between the borehole heat exchangers (BHE) and the ground [48]. To link each lithology class mentioned above with a thermal conductivity value, the database of the German standard VDI 4640 [47] was used. After this exercise, it was possible to produce the spatial GIS thermal conductivity map.

2.4.1.3. Materials consolidation. Drilling is a crucial process for the installation of SGE and is considered one of the main factors determining the feasibility of SGE, as the associated costs can reach up to 50\% of SGE's total installation costs [49]. Material consolidation determines the selection of the most suitable drilling technique and affects the drilling time and cost by requiring the application or not of a casing. Well-consolidated rock is often easily drilled with a suitable method, and the walls of the boreholes are stable, whereas non-consolidated rocks (sediments) produce

Table 4

Systematization of IUCN classification concerning the protected areas into an area's protection associated to SGEs installation.

\begin{tabular}{|c|c|c|}
\hline $\begin{array}{l}\text { Protection of } \\
\text { areas }\end{array}$ & Definition & IUCN classification \\
\hline $\begin{array}{l}\text { Not allowed } \\
\text { areas }\end{array}$ & $\begin{array}{l}\text { Areas where due to its natural, cultural, or geological characteristics, they are strictly protected and therefore } \\
\text { any kind of human activity is not allowed. }\end{array}$ & Ia Strict nature Reserve \\
\hline $\begin{array}{l}\text { May be } \\
\text { restricted } \\
\text { areas }\end{array}$ & $\begin{array}{l}\text { Areas where due to its natural, cultural, or geological characteristics human activity is likely to be restricted and } \\
\text { protection level differs from one country to another. }\end{array}$ & $\begin{array}{l}\text { Ib Wilderness area } \\
\text { II National Park } \\
\text { III natural Monument or feature } \\
\text { IV Habitat/species management area } \\
\text { V Protected landscape/seascape } \\
\text { VI Protected area with sustainable use } \\
\text { of natural resources. }\end{array}$ \\
\hline $\begin{array}{l}\text { Non-protected } \\
\quad \text { areas }\end{array}$ & Areas where due to its natural, cultural, or geological characteristics human activity is not restricted. & \\
\hline
\end{tabular}




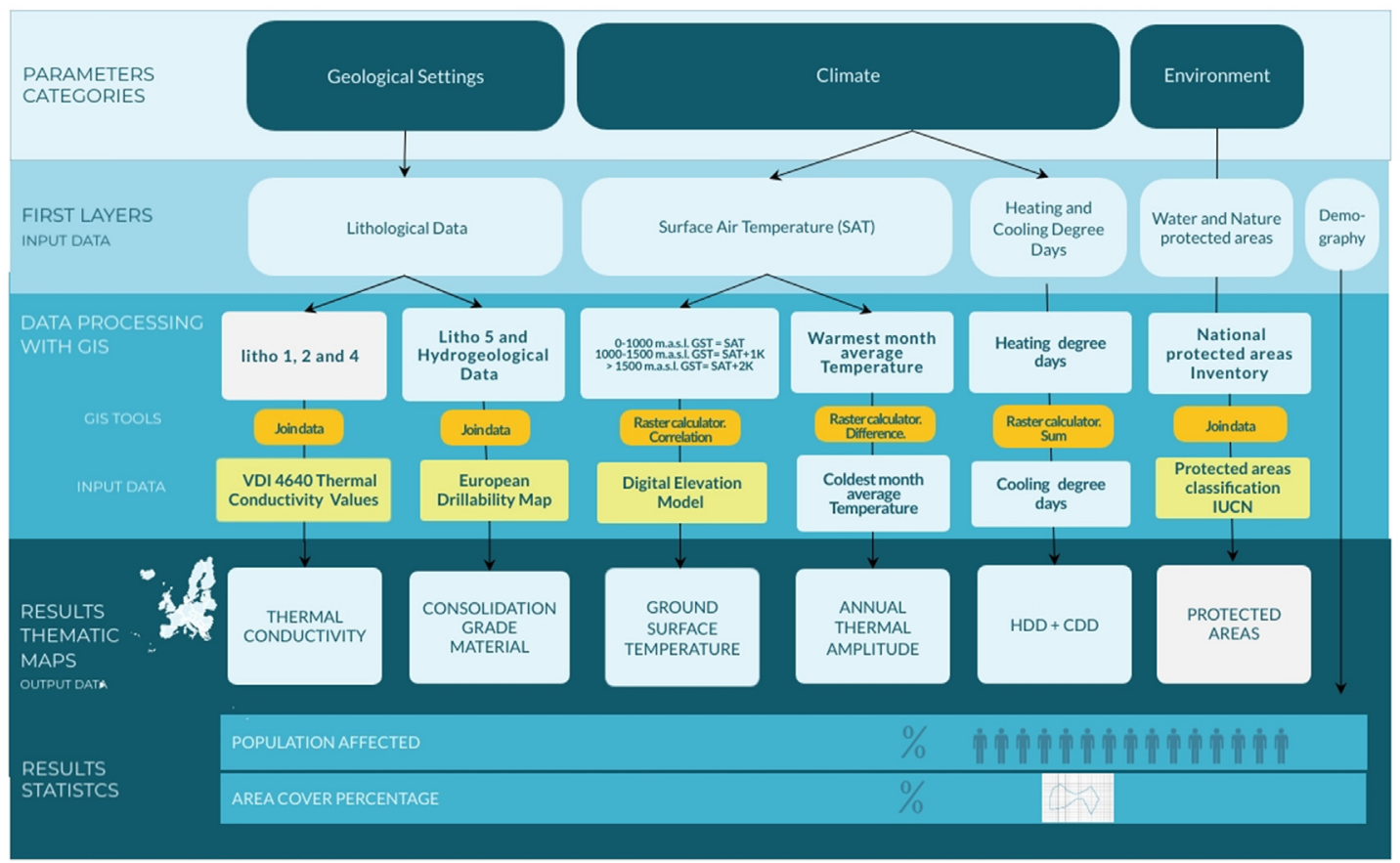

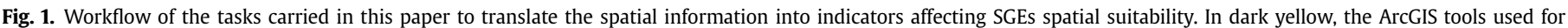

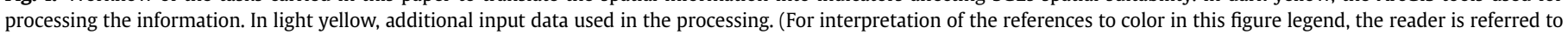
the Web version of this article.)

possible collapse of the borehole and eventually the need for a temporary or permanent casing. Moreover, site-specific hydrological conditions govern the efficiency of SGE and may determine the feasibility of the systems. In case of groundwater presence, the ground heat extraction rate may be higher, although depending on the consolidation of the rock.

On the basis of these premises, in order to assess the economic and efficiency feasibility of the supposed SGEs in the study area, three groups were differentiated, based on the material consolidation grade: Unconsolidated materials, Partly consolidated materials, and Consolidated materials. These groups were overlapped with the Drillability Map with its drilling techniques and associated with the hydrogeological and aquifer productivity, both mentioned above. This classification allowed to make a spatial assessment of the expected drilling techniques, aquifer types, productivity segment and the relationship between them based on the rock consolidation grade group, based on which it was possible to produce the spatial GIS Materials Consolidation Grade map.

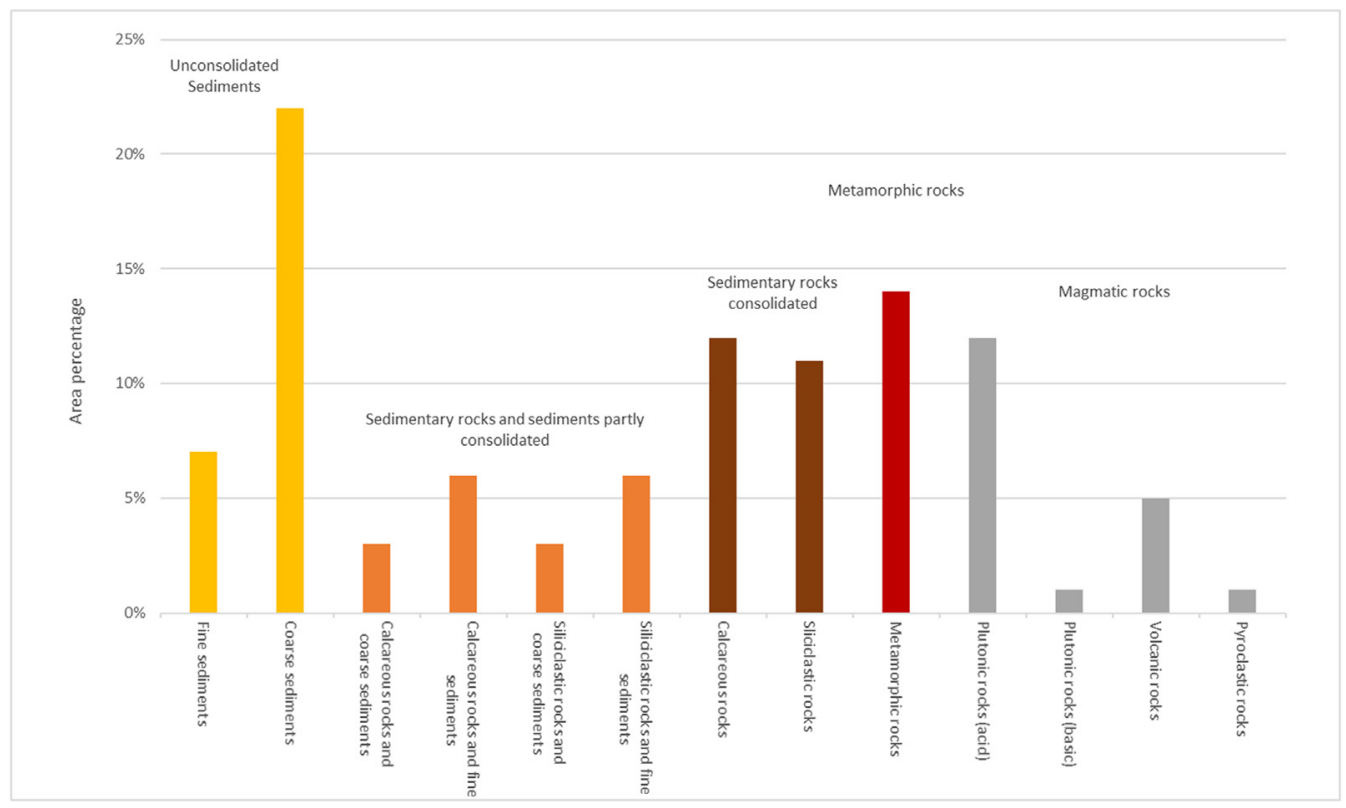

Fig. 2. Lithologies area percentage. 

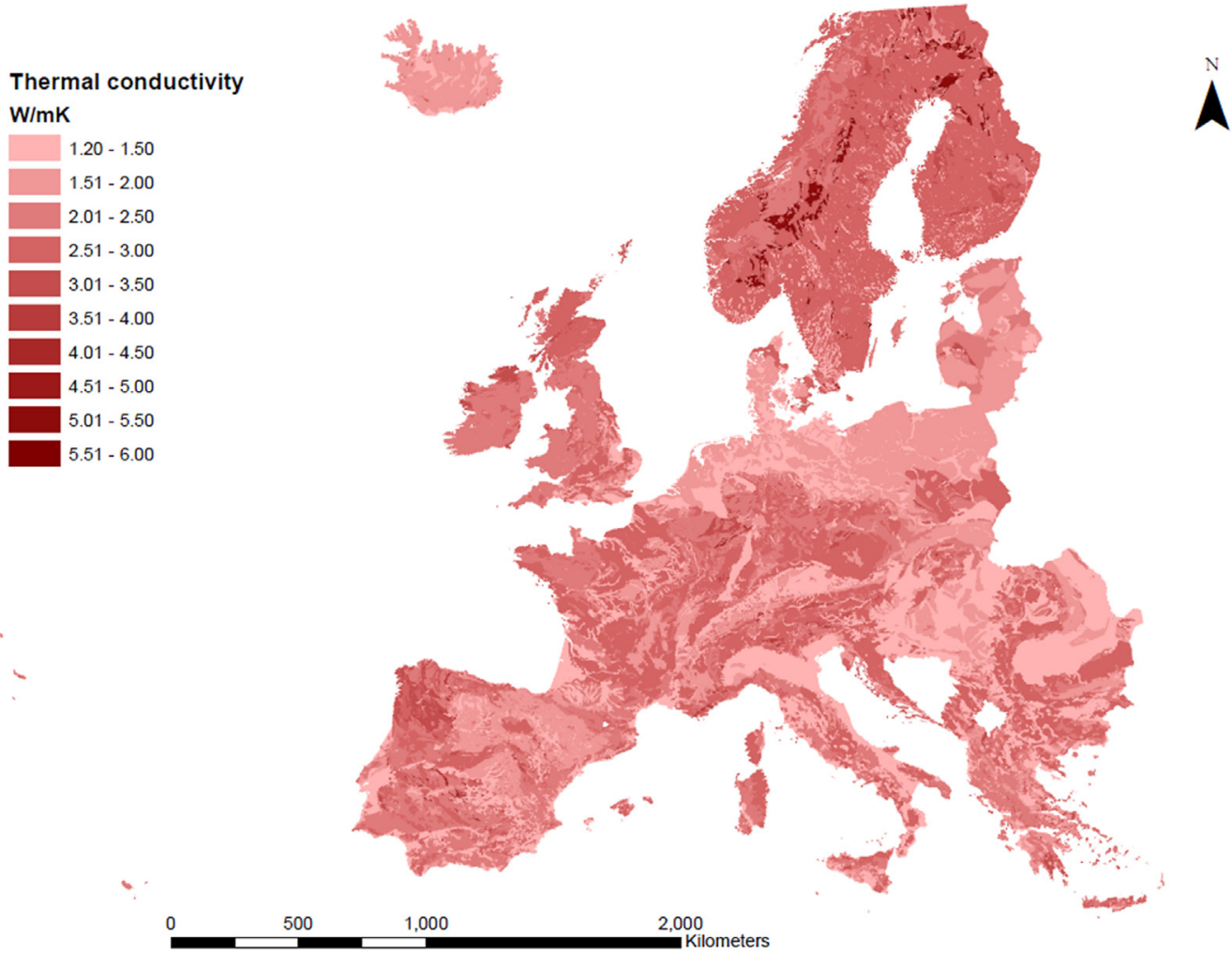

Fig. 3. Thermal conductivity map.

Consolidation grade rock

Consolidated rock

Partly cons olidated rock

Unconsolidated rock

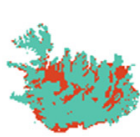

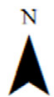

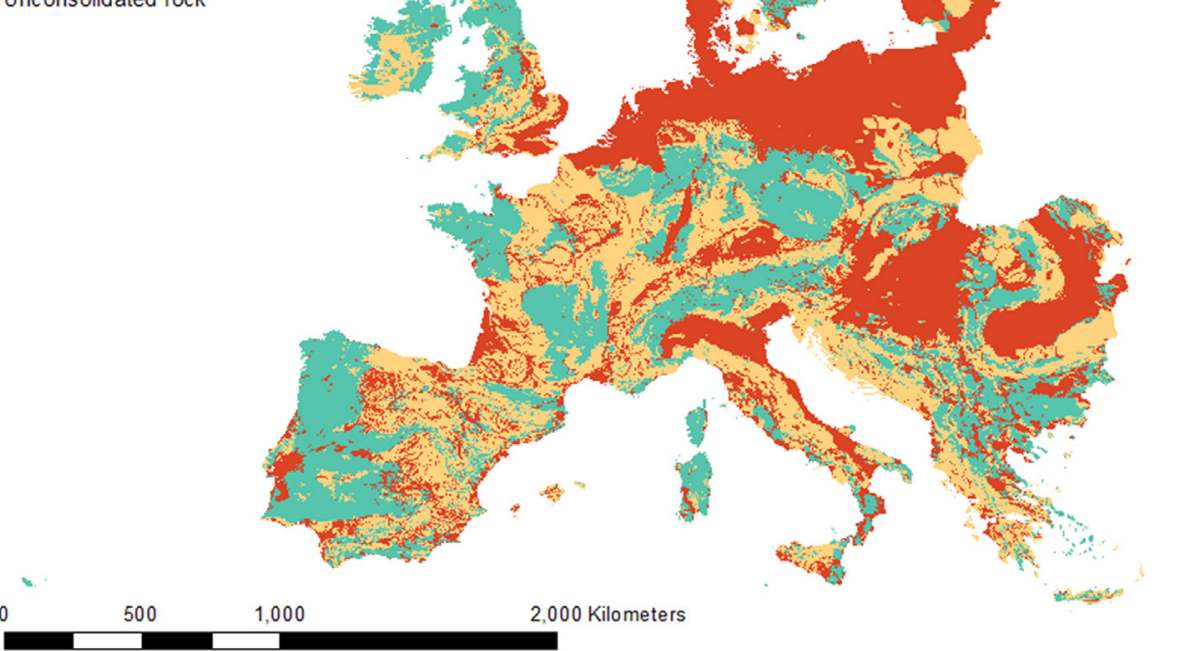

Fig. 4. Consolidation grade rock map. 
Table 5

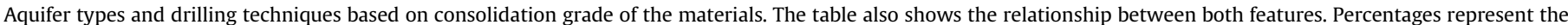
share with respect to the total area for aquifers and for drilling techniques separately.

\begin{tabular}{|c|c|c|c|}
\hline Aquifer type & Unconsolidated materials & Partly consolidated materials & Consolidated materials \\
\hline Highly productive fissured aquifers (including karstified rocks) & $1 \%$ & $4 \%$ & $6 \%$ \\
\hline Highly productive porous aquifers & $7 \%$ & $1 \%$ & $2 \%$ \\
\hline Locally aquiferous rocks, porous or fissured & $11 \%$ & $7 \%$ & $10 \%$ \\
\hline Low and moderately productive fissured aquifers (inc. karstified rocks) & & $7 \%$ & $5 \%$ \\
\hline Low and moderately productive porous aquifers & $18 \%$ & $2 \%$ & $1 \%$ \\
\hline Practically non-aquiferous rocks, porous or fissured & $2 \%$ & $2 \%$ & $14 \%$ \\
\hline Total & $39 \%$ & $23 \%$ & $38 \%$ \\
\hline \multicolumn{4}{|l|}{ Drilling technique } \\
\hline Chevron with casing & $2 \%$ & & \\
\hline \multicolumn{4}{|l|}{ Chevron without casing } \\
\hline Down-hole hammer with casing & & $17 \%$ & $3 \%$ \\
\hline Down-hole hammer without casing & & $4 \%$ & $43 \%$ \\
\hline Easy drill pilling without casing & $10 \%$ & $2 \%$ & \\
\hline Tricone with casing & & $17 \%$ & \\
\hline Tricone without casing & & & $2 \%$ \\
\hline Total & $12 \%$ & $40 \%$ & $48 \%$ \\
\hline
\end{tabular}

\subsubsection{Indicators derived from climatic datasets}

2.4.2.1. Ground surface temperature (GST). GST is considered of paramount importance in any assessment of shallow geothermal potential as it determines the heat content in the first meters of the ground. GST depends linearly on the altitude and is equal to Surface Air Temperature (SAT) up to 1500 m.a.s.l., and above this altitude GST is affected by difficulty foreseeable local deviations ranging from $\pm 1-2 \mathrm{~K}[50]$.

In this study, a linear approach has been used considering the following ranges and corrections derived from altitude:

- From 0 to 1000 m.a.s.l. GST is equal to SAT (thus no altitude dependency)

- Between 1000 and 1500 m.a.s.l. GST is SAT+1K and

- Above 1500 m.a.s.l GST is SAT+2 K.

Calculations of this indicator were done using average temperature and DEM spatial information available for the altitude ranges.

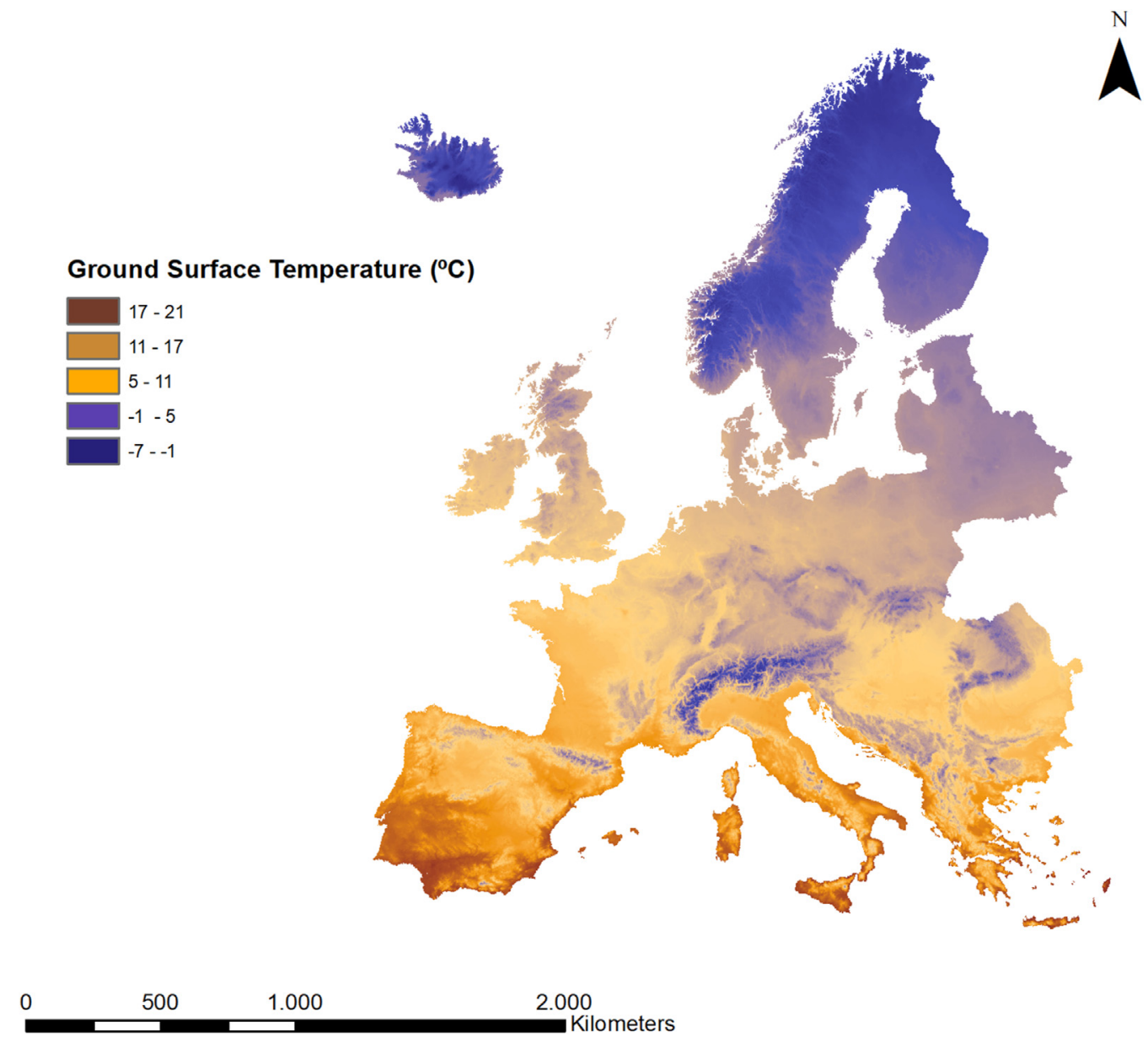

Fig. 5. Ground surface temperature map. 


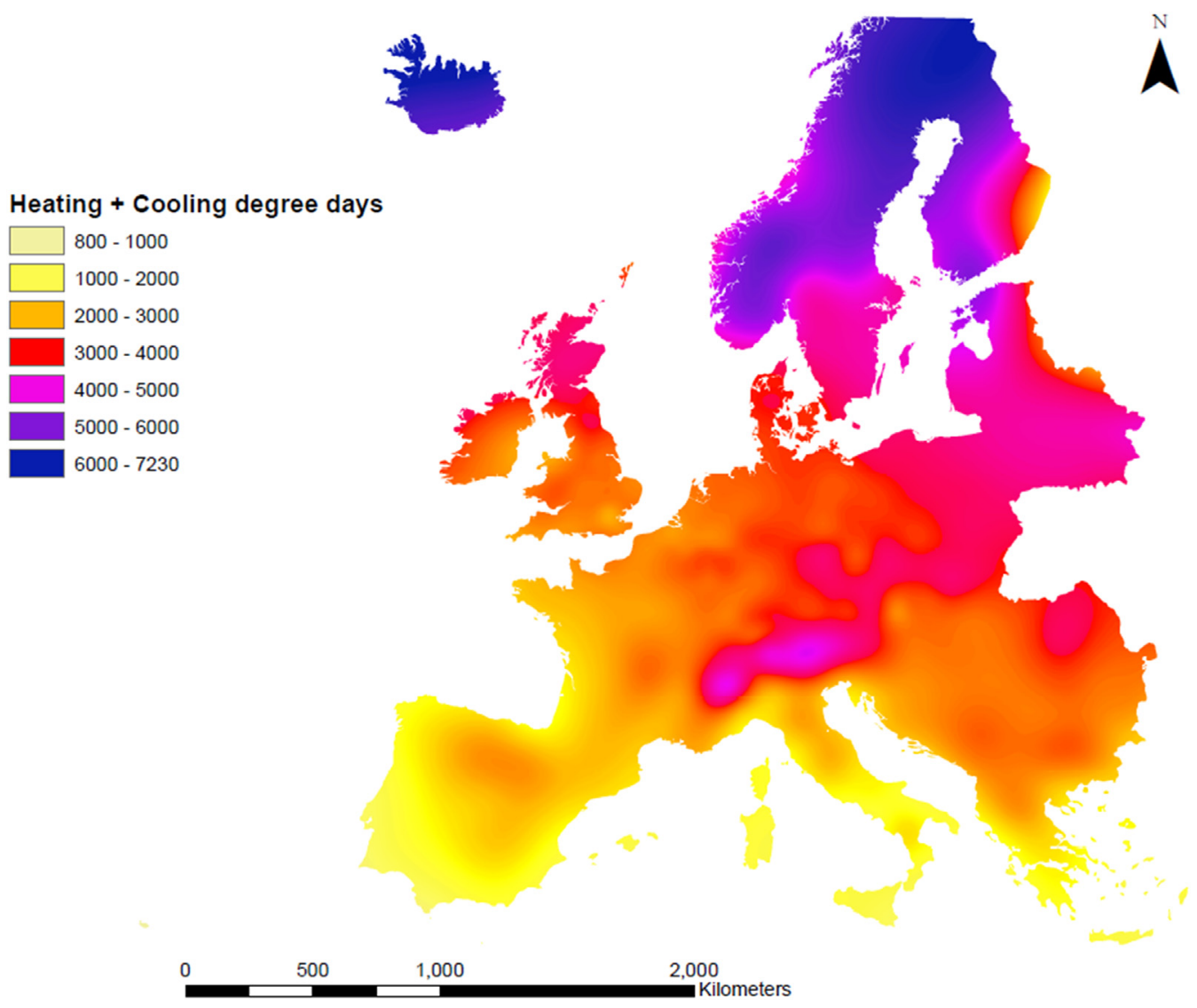

Fig. 6. Heating + Cooling degree days map.

2.4.2.2. Annual thermal amplitude. Annual thermal amplitude is of great importance when it comes to determining the suitability of providing space heating and/or cooling with GSHPs compared to more conventional Air-Source Heat Pumps (ASHPs). Compared to ground, ambient air shows a wider variation in temperature allyear-round and on a daily basis, which reduces the COP [51]. Larger thermal amplitudes tend to favor the use of GSHPs in comparison to ASHPs due to an increasing efficiency surplus.

Annual thermal amplitude was calculated as the difference between annual maximum temperature of the warmest month and minimum temperature of the coldest month using temperature data mentioned above. This dataset provides layers containing average temperature of every month of the year. An assessment of the temperature values of the spatial datasets for the whole year was carried out in order to determine when the highest and the lowest temperatures are given. They were found in July and in January, respectively. Finally, a difference of the two layers was calculated with GIS and displayed in the annual thermal amplitude map.

2.4.2.3. Heating and cooling degree days $(H D D+C D D)$. Heating and cooling degree days are important assessment indicators as well, as they offer a rough indication about the energy demand to be expected to heat and eventually cool a dwelling. In areas where HDD and CDD values are low, the demand is lower than for equivalent buildings in higher HDD/CDD areas. This affects the use factor (total amount of equivalent full load hours the system is in operation compared to the total number of hours in a heating/cooling season) of a given GSHP system and hence its techno-economic feasibility. As a rough indication of the total annual energy demand in both heating and cooling mode, the sum of HDD and CDD annual values was calculated using the data mentioned previously. However, this indicator must be interpreted with special care, as different building typologies will show a substantial variation in their energy within the same HDD/CDD region. A more comprehensive correlation between climate, building type and building energy needs is discussed in Ref. [52].

\subsubsection{Indicators derived from environmental datasets}

2.4.3.1. Protected areas. Identification of nature protection areas is a must in this study as it will determine the areas where SGE exploitation is likely to be restricted or even banned. Areas with restrictions may limit the suitability and profitability of SGEs. This is mainly due to the bureaucratic process of permitting being longer and costlier. Based on IUCN protected areas classification the EEA spatial information mentioned above was split in three different zones determining the SGE exploitation restriction grade shown in Table 4 "Protection areas".

For SGE, another type of protection concerning the groundwater is of importance. As groundwater protection areas, zones around drinking water wells, etc. usually are regulated on a regional basis, and there is no European-wide database yet in existence. Hence there will be further restrictions to the use of SGE systems that cannot be included in the current study and will need to be assessed on a regional scale.

\subsection{GIS analysis}

The GIS software used for the analysis was ArcGIS from the ESRI family (version 10.2.1) [53]. A combination of raster and vector data were used as input in the analysis. All vector datasets were rasterized for the analysis in order to make one consistent database. 


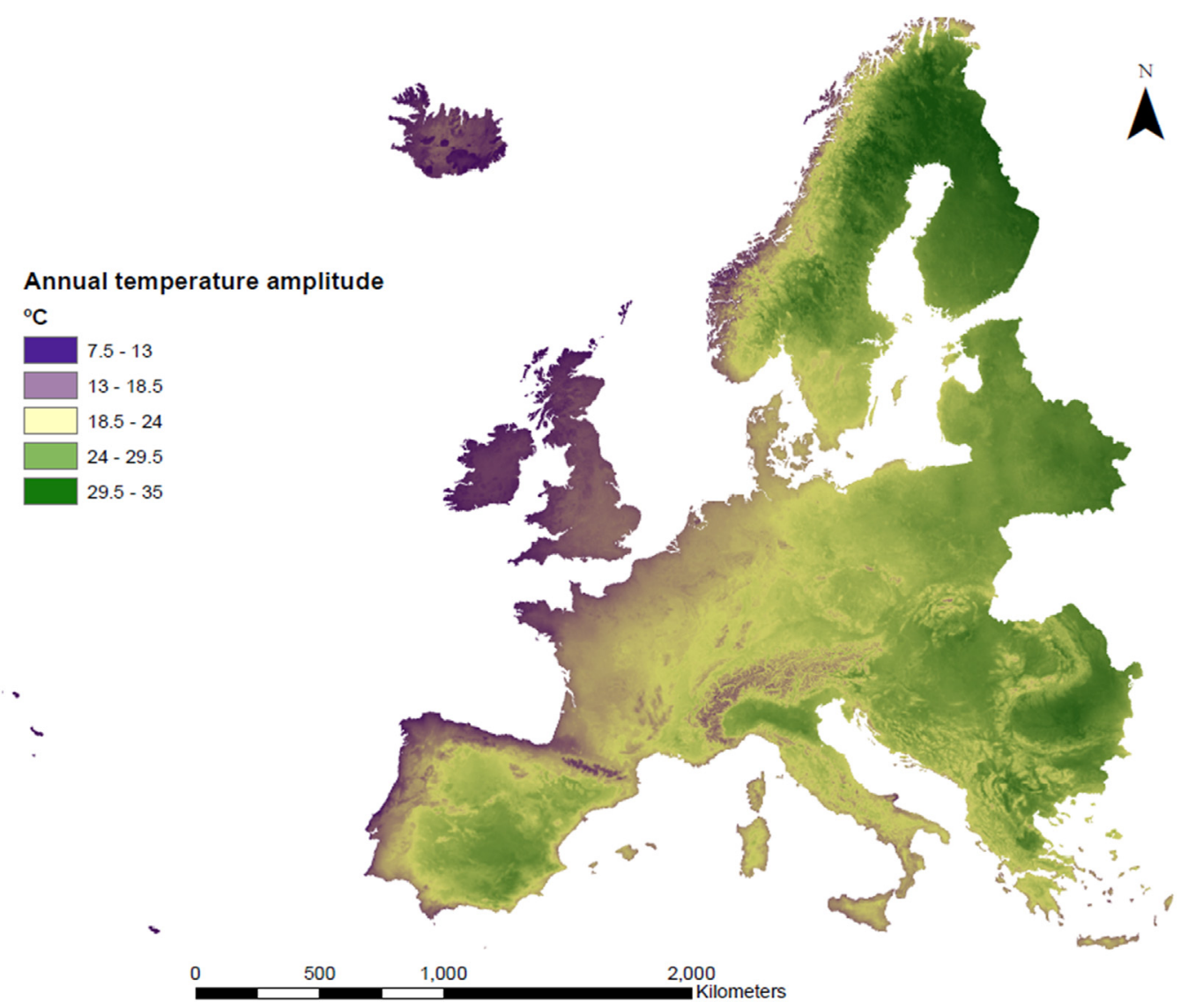

Fig. 7. Annual temperature amplitude map.

Two main tools were utilized: the spatial analysis tool "raster calculator" and the "joining data" from the ArcMap toolset. The "raster calculator" allows to create and execute map algebra expressions outputting a raster. This tool was used to process data for ground surface temperature, annual thermal amplitude, and HDD + CDD maps. The "join data" tool is designed to transfer information from one layer to another based on the type of spatial relationship defined or based on a common attribute shared between two datasets. This tool was used to process data for thermal conductivity, materials consolidation grade and protected area maps. Output raster resolution was 2.5 arcminutes $\left(\sim 3.6 \mathrm{Km}^{2}\right)$ in all cases. Fig. 1 shows a schematic of the full procedure.

\section{Results and discussion}

Each output indicator was divided into several classes. Then, for each of these classes and indicators, the relative (percent) area was assessed, as well as the relative (percent) population. The relative area and resulting maps are exhibited in sections 3.1 to 3.3 and population results are shown in 3.4.

\subsection{Geological factors}

\subsubsection{Lithology}

Lithology (Fig. 2) is by far dominated by unconsolidated sediments representing $29 \%$ of the total lithology characterized by the large presence of coarse sediments. Sedimentary rocks with consolidated sediments are the second largest group accounting for $23 \%$ of the total area percentage with a balanced presence between siliciclastic and calcareous rocks. Magmatic rocks cover 19\% of the area characterized by a high presence of acid plutonic rocks. Sedimentary rocks and sediments partly consolidated account for $18 \%$ of the area percentage and lastly, metamorphic rocks cover $14 \%$ of the total area.

\subsubsection{Thermal conductivity}

Thermal conductivity values (Fig. 3) range from 1.2 to $6 \mathrm{~W} / \mathrm{mK}$ and were divided into 10 classes. The $2.5-3 \mathrm{~W} / \mathrm{mK}$ class comprises the largest share with $28 \%$ of the total area and it is equally spread along the different territories. $1.2-1.5 \mathrm{~W} / \mathrm{mK}$ class covers almost $22 \%$ of the area and is the second most widespread thermal conductivity group. Very similar are the values found in the class ranging between 1.5 and $2 \mathrm{~W} / \mathrm{mK}$, representing the third largest conductivity class.

A large part of Belgium, The Netherlands, Northern Germany, Northern Poland, Hungary, Latvia and Lithuania fall into these two classes, as well as the East coast and Northern plains of Italy. Group $2-2.5 \mathrm{~W} / \mathrm{mK}$ makes up $17 \%$ of area percentage and is the fourth most frequent class. Within this class can be clearly defined a huge part of France, the United Kingdom, South Germany and Poland as well as the west of Spain and Portugal. Finally, a small 3\% of cover percentage possesses values ranging from 3 to $6 \mathrm{~W} / \mathrm{mK}$ which can be found within the borders of Sweden and Norway.

\subsubsection{Materials consolidation}

Based on the geology, three different groups were made based on rock consolidation: unconsolidated, partly consolidated and consolidated as displayed in Fig. 4. Among other features, they determine the drilling technique and the aquifer likely associated when drilling the BHE needed for the GSHPs. The area classified as 


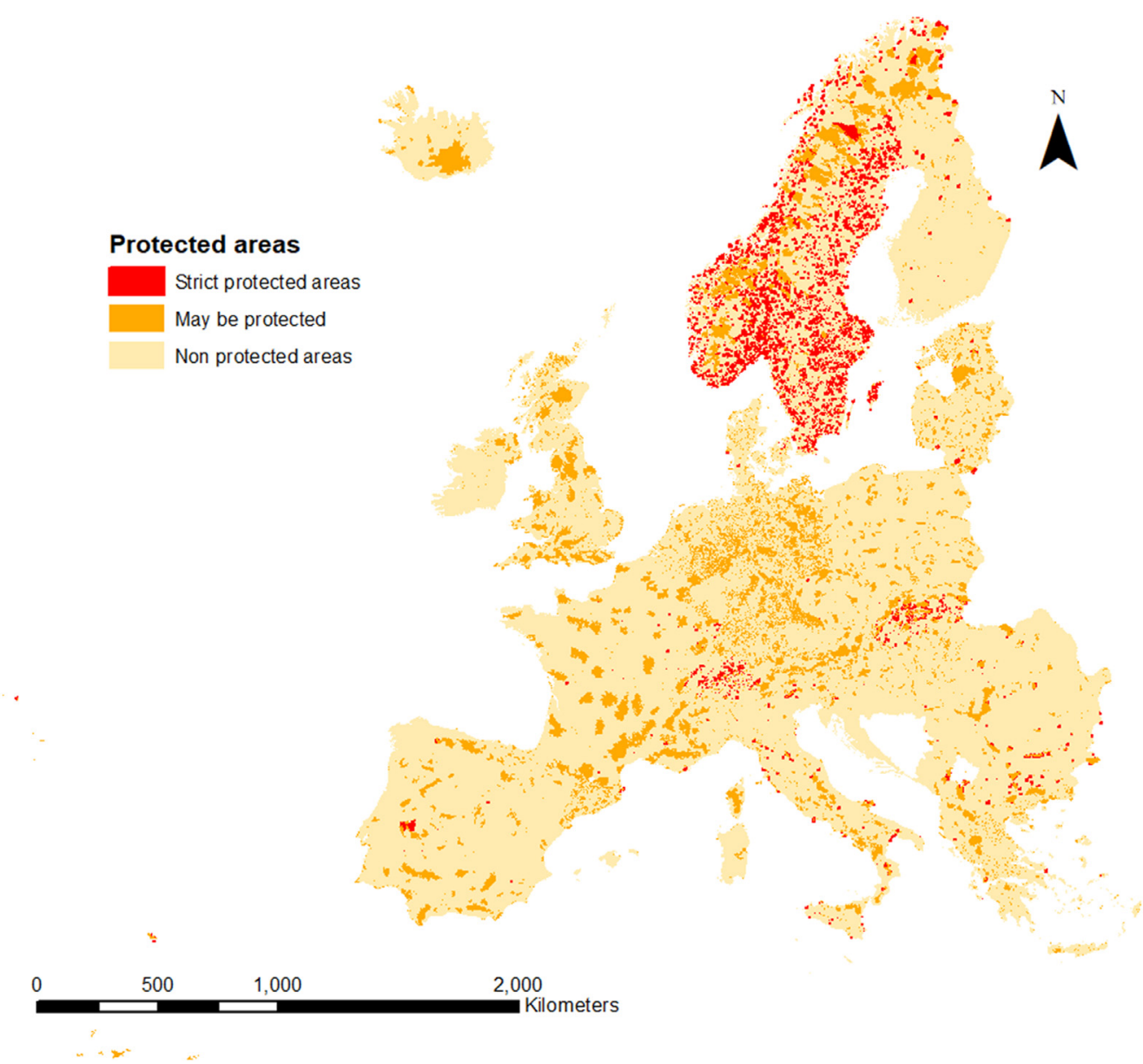

Fig. 8. Protected areas map.

consolidated rocks comprises $53 \%$ of the total area (Fig. 10), constituting the largest class which can be clearly discerned in entire countries such as Portugal, Sweden and Norway. Porous aquifers are basically found here with low to moderate, locally aquiferous rocks and highly productive aquifers in this order of frequency, as displayed in Table 5. Tricone or Chevron with casing is considered the most appropriate technique and the most extensively used. The partly consolidated class covers $18 \%$ of the area and is extended heterogeneously across the continent. Fissured and porous aquifers are mostly found here, with the aquifer productivity varying from low to high, and locally aquiferous rocks could be present. Down-hole hammer and Tricone, both with casing, are the most applicable drilling techniques to be used in these conditions. And finally, the area under the unconsolidated group comprises $29 \%$ of the total area. This class represents almost the whole area in countries such as Sweden and Norway and extends into large territories in the Northern part of the United Kingdom, Western Spain, and Portugal, among others. Here, practically nonaquiferous rocks, porous and fissured are the most common aquifers, although locally aquiferous rocks or highly productive fissured rocks are also present. Down-hole hammer without casing is by far the predominant drilling technique considered here. It is considered the most appropriate technique in $43 \%$ of the total area and thus represents the most widespread technique.

\subsection{Climatic factors}

\subsubsection{Ground surface temperature}

Ground surface temperatures resulting values range from $-7{ }^{\circ} \mathrm{C}$ to $21^{\circ} \mathrm{C}$, as represented in Fig. 5 and were divided in 5 classes. 5 to $11{ }^{\circ} \mathrm{C}$ class comprises the largest part concerning the area percentage with almost $44 \%$ of the territory, followed by $-1^{\circ}$ to $5{ }^{\circ} \mathrm{C}$ class and 11 to $17{ }^{\circ} \mathrm{C}$ class with each one covering around $25 \%$ of the territory. Lastly, -7 to $-1{ }^{\circ} \mathrm{C}$ and 17 to $21^{\circ} \mathrm{C}$ classes cover respectively only 2 and $3 \%$ of the whole area. As expected, temperature values increase as going ahead to the South and vice versa.

\subsubsection{Heating + Cooling degree days}

HDD + CDD values vary between 800 and 7230 and were segmented in 7 classes. This indicator is characterized by the large presence of both 2000 to 3000 and 3000 to 4000 classes, with approximately $70 \%$ of area percentage altogether. Concerning the 3 classes of highest values (4000-7230), they together cover $14 \%$ of the total area. Both 800 to 1000 and 1000 to 2000 classes account for a similar area share of 14\%. Fig. 6 show the highest values in Northern countries and how values diminish as going down to the Southern countries. Other violet color zones can be seen in the map that correspond to mountain groups.

\subsubsection{Annual thermal amplitude}

Annual temperature amplitude values range from 7.5 to $35{ }^{\circ} \mathrm{C}$ and were divided in 5 classes. Looking at Fig. 7, as heading north- 


\section{Population Density} Inhabitants/km2

\begin{tabular}{|l|l}
\hline & 0 \\
\hline & 1 \\
\hline & $2-6$ \\
\hline & $7-11$ \\
\hline & $12-51$ \\
& $52-101$ \\
$102-201$ \\
$202-501$ \\
$502-1,001$ \\
$1,002-2,001$ \\
$2,002-5,001$ \\
$5,002-10,001$ \\
$10,002-25,000$
\end{tabular}
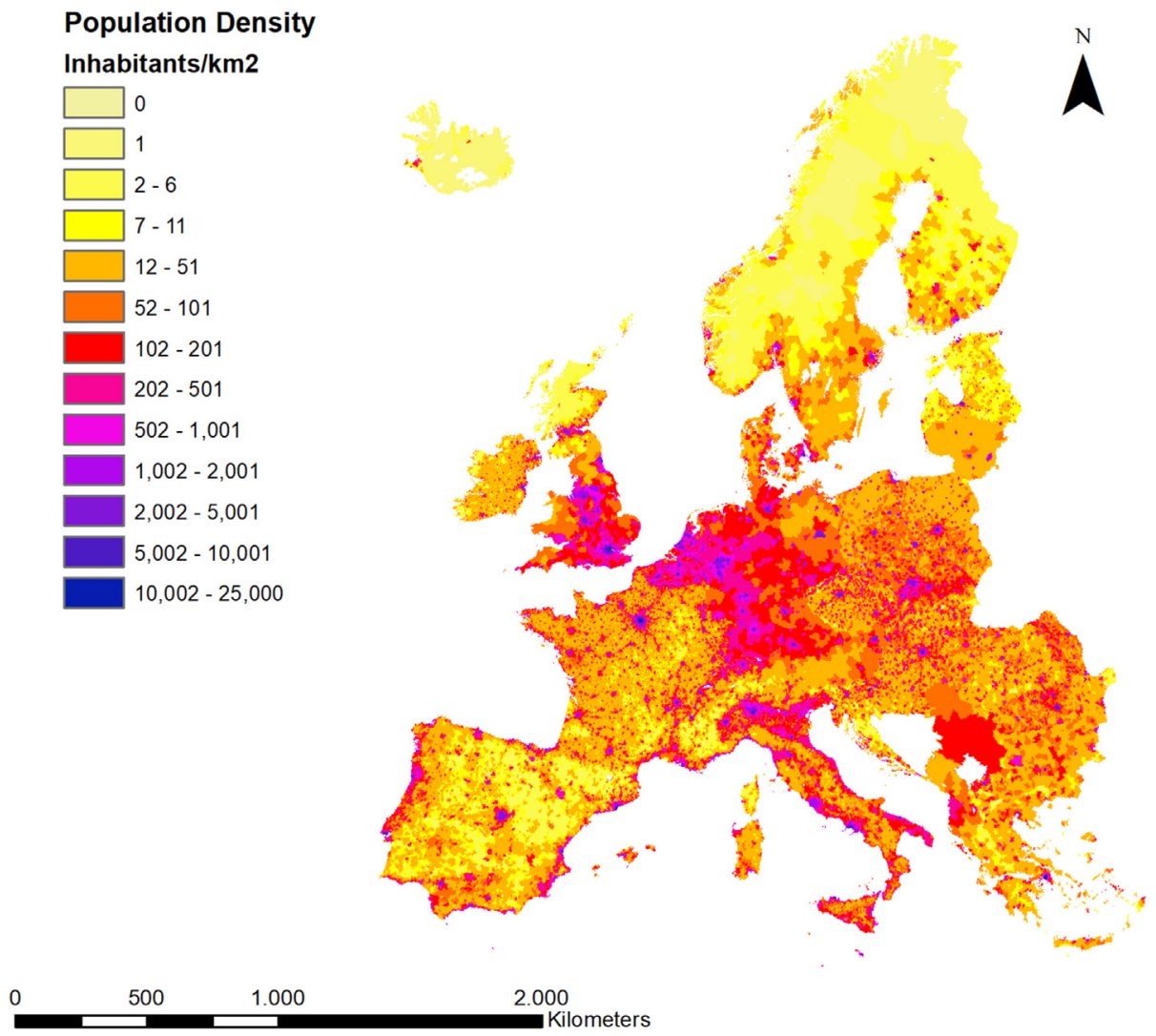

Fig. 9. Population density map.

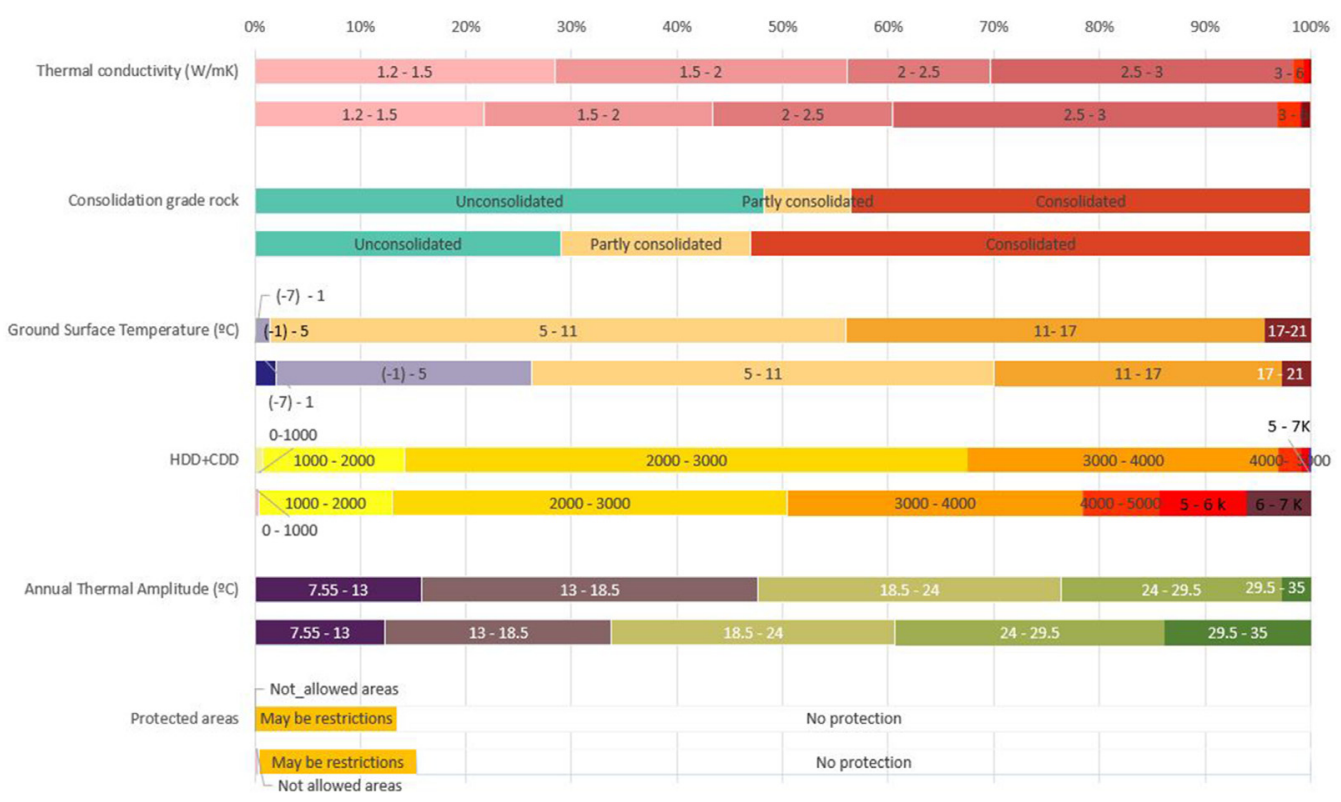

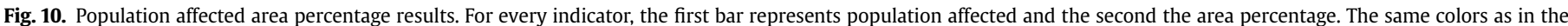
maps were used. (For interpretation of the references to color in this figure legend, the reader is referred to the Web version of this article.)

west within the study area, a downscale tendency of values is observed, and the lower values are found in coastal areas. In general, coastal areas along the territories present lower values compared to territories in the interior. The different classes follow a similar pattern as climate zone maps in Europe. The highest amplitudes are found in Mediterranean and Continental climates whilst the lowest are found in Atlantic, Polar and Mountain climates. On the other hand, around $50 \%$ of the area comprises amplitudes between 7.5 and $18.5^{\circ} \mathrm{C}$ (two first classes) whilst the other $50 \%$ presents amplitudes ranging from 18.5 to $35^{\circ} \mathrm{C}$. 


\subsection{Environmental factors}

\subsubsection{Protected areas}

Protected area results are classified into three groups: areas where the exploitation of SGE is not allowed, areas where the exploitation may be restricted, and non-protected areas, as shown in Fig. 8. Areas where the exploitation is not allowed extend to $0.08 \%$ of the total area and only can be found mostly in Norway, Sweden, Switzerland, and Slovakia. Areas where the exploitation of SGE may be restricted cover $14.92 \%$ of the total area and occupy, for the most part, certain countries such as Germany, the United Kingdom, Poland, Czech Republic, Austria, Denmark, and Switzerland.

Lastly, $85 \%$ of the area was categorized as non-protected areas and can be seen mainly in Southern countries and Finland. Possible additional, local restrictions for groundwater protection are not included (see 2.4.3).

\subsection{Areas versus population}

Fig. 9 shows the map with the population density data and Fig. 10 shows the outcomes for all the output indicators that were analyzed. From it, the following can be observed. In general, as thermal conductivity values increase, both area percentage and population affected values decrease. Even so, there is an exception with $2.5-3 \mathrm{~W} / \mathrm{mK}$ class that comprises the largest share of the population and area with more than $28 \%$ and $36 \%$ respectively. Nevertheless, the vast majority of the population, $70 \%$, is located in territories with values ranging from 1.2 to $2.5 \mathrm{~W} / \mathrm{mK}$, which belong to the first three classes. And just a small share of $1.5 \%$ of the population lives in areas with values higher than $3 \mathrm{~W} / \mathrm{mK}$, which extend to $3 \%$ of the area.

Unconsolidated materials cover $28 \%$ of the territory while almost $50 \%$ of the population is concentrated there. Partly consolidated materials cover $17 \%$ of the area while $8 \%$ is the population affected. Finally, consolidated materials comprise $55 \%$ of the territory and affect $44 \%$ of the total population.

As for Ground Surface Temperature population affected, the situation changes compared to the area, mostly in those regions with the lowest and the highest temperatures. $4.4 \%$ of the population lives in areas where the average ground surface temperature ranges from 17 to $21{ }^{\circ} \mathrm{C}$, almost $40 \%$ of the population resides in the 11 to $17{ }^{\circ} \mathrm{C}$ class whilst $54.4 \%$ of the population is in the 5 to $11{ }^{\circ} \mathrm{C}$ class. Finally, only $1.5 \%$ of the population resides in $-1-5{ }^{\circ} \mathrm{C}$ class and no population was found where the average ground surface temperature is below.

The Heating plus Cooling degree days indicator is characterized by the large presence of both 2000 to 3000 and 3000 to 4000 classes in area percentage. These two classes comprise almost $85 \%$ of the total population altogether. Concerning the highest values classes (4000-7230), together they cover $21.6 \%$ of the total area while only $3 \%$ of the population resides there. Lastly, the two classes in the 0 to 2000 range account for a similar share of $14 \%$ and $13 \%$ for population and area, respectively.

As for Annual Temperature Amplitude, population and area percentage generally are quite equally spread. Notwithstanding, the 29.5 to $35{ }^{\circ} \mathrm{C}$ class extends to $16 \%$ of the total area but only a fractional $3 \%$ of population is found there.

And lastly, regarding areas classified as not allowed due to their environmental protection, while they extend to $0.08 \%$ of the total area, they don't have any population associated, of course. Areas where the exploitation of SGE may be restricted cover $15 \%$ of the area where $13.5 \%$ of the total population is found. And $85 \%$ of the area was categorized as non-protected area where $85 \%$ of population lives.

\subsection{Identifying potential areas: example case in South Spain}

From the maps of the various indicators, regions in Europe can be identified where the environmental factors are favorable for the exploitation of this energy source and used to evaluate how this compares with its current implementation level. As an example, an area is selected in southeastern Spain (Murcia region). For this region, the thermal conductivity indicator (Fig. 10) shows the presence of high values (between 1.5 and $3.2 \mathrm{~W} / \mathrm{mK}$ ). The rest of the indicators (average air and underground temperatures, expected heating and cooling demand, etc.) also show favorable values, although there are a few areas with environmental restrictions. Thus, it can be concluded that this area possesses adequate natural characteristics for the exploitation of geothermal energy.

Despite this area accounting for good physical properties, the Regional Energy Master Plan (2016-2020) shows that this energy source is currently not considered as a realistic energy source for renewable heating and cooling [54]. In this document, up to 100 different actions to promote the energy efficiency and the use of renewable energies are proposed although only one of them includes geothermal energy as an option. Moreover, the exploitation level of the shallow geothermal resource for heating and cooling is unknown, as there is no official registration for this type of energy installations. Interestingly, the shallow resource has been historically exploited in this region for heating greenhouses, agriculture being one the most important economic activities. In addition, this region accounts for long hot seasons with high cooling needs which are currently completely covered by conventional electric heat pumps.

According to a study of the Regional Government [55], the lack of specific regulations concerning the drilling of boreholes for this type of activities is hampering the exploitation of this resource, but also the lack of public awareness on the potential of this technology. This causes a lack of political and economic support and prevents SGE becoming a relevant energy source for this region. Recently, the regional government has funded some experimental plants which show that there is an intention to tap into this geothermal resource.

The indicator maps can also be used as input into a MultiCriteria Decision-Making (MCDM) framework. The MCDM-GIS combination has been widely used to obtain the evaluation of the

Table 6

Weight of criteria and indicators/factors for the case of applying MCDM with GIS in Murcia Area.

\begin{tabular}{|c|c|c|c|c|c|c|}
\hline \multirow[t]{2}{*}{ Order } & \multirow[t]{2}{*}{ Indicator } & \multirow[t]{2}{*}{ Unit } & \multirow[t]{2}{*}{ Weight } & \multicolumn{3}{|l|}{ Suitability level } \\
\hline & & & & 1 (Acceptable) & 2 (Good) & 3 (Excellent) \\
\hline $1 \mathrm{st}$ & Thermal conductivity & $\mathrm{W} / \mathrm{mK}$ & 0.6 & $1.2-2.5$ & $2.51-4$ & $4.01-6$ \\
\hline 2nd & $\mathrm{HDD}+\mathrm{CDD}$ & & 0.1 & $800-2000$ & $2001-4300$ & $4301-7230$ \\
\hline 3rd & Consolidation grade rock & & 0.1 & Consolidated & Partly con. & Unconsolidated \\
\hline 4th & Ground Surface temperature & ${ }^{\circ} \mathrm{C}$ & 0.09 & $(-7.2)-2$ & $2-18$ & $18-21$ \\
\hline 5 th & Protected areas & & 0.07 & & May be restrictions & Non protected areas \\
\hline 6th & Annual temperature amplitude & ${ }^{\circ} \mathrm{C}$ & 0.04 & $7.5-18$ & $18-24$ & $24-35$ \\
\hline
\end{tabular}



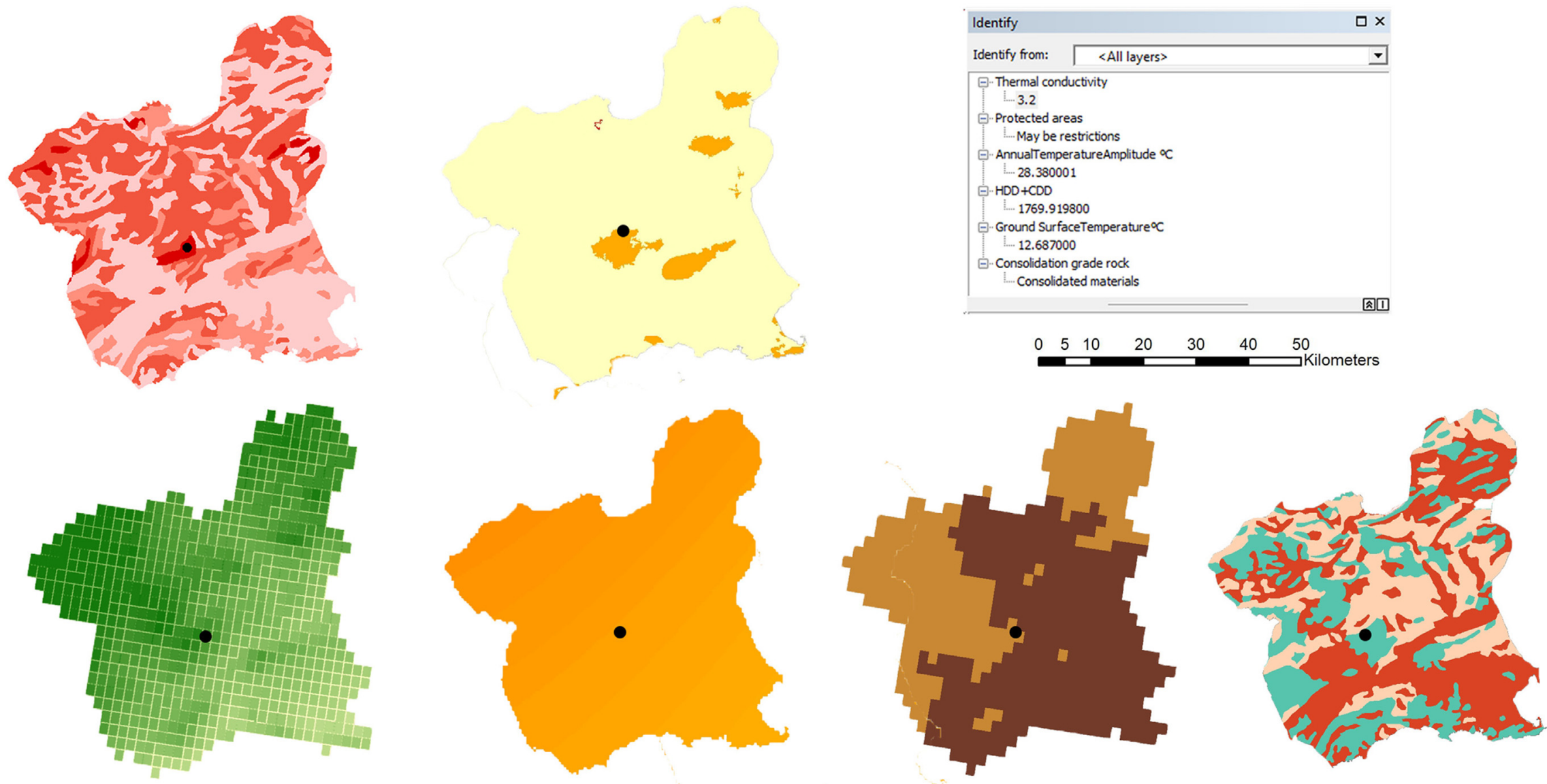

Fig. 11. Visualization of the thematic maps values of a given point in Murcia Region, located in Southern Spain. From left to right, the extraction maps are: (1) Thermal Conductivity, (2) Protected areas, (3) Annual Temperature amplitude, (4) Heating + Cooling degree days, (5) Ground surface Temperature, and (6) Consolidation grade rock. 


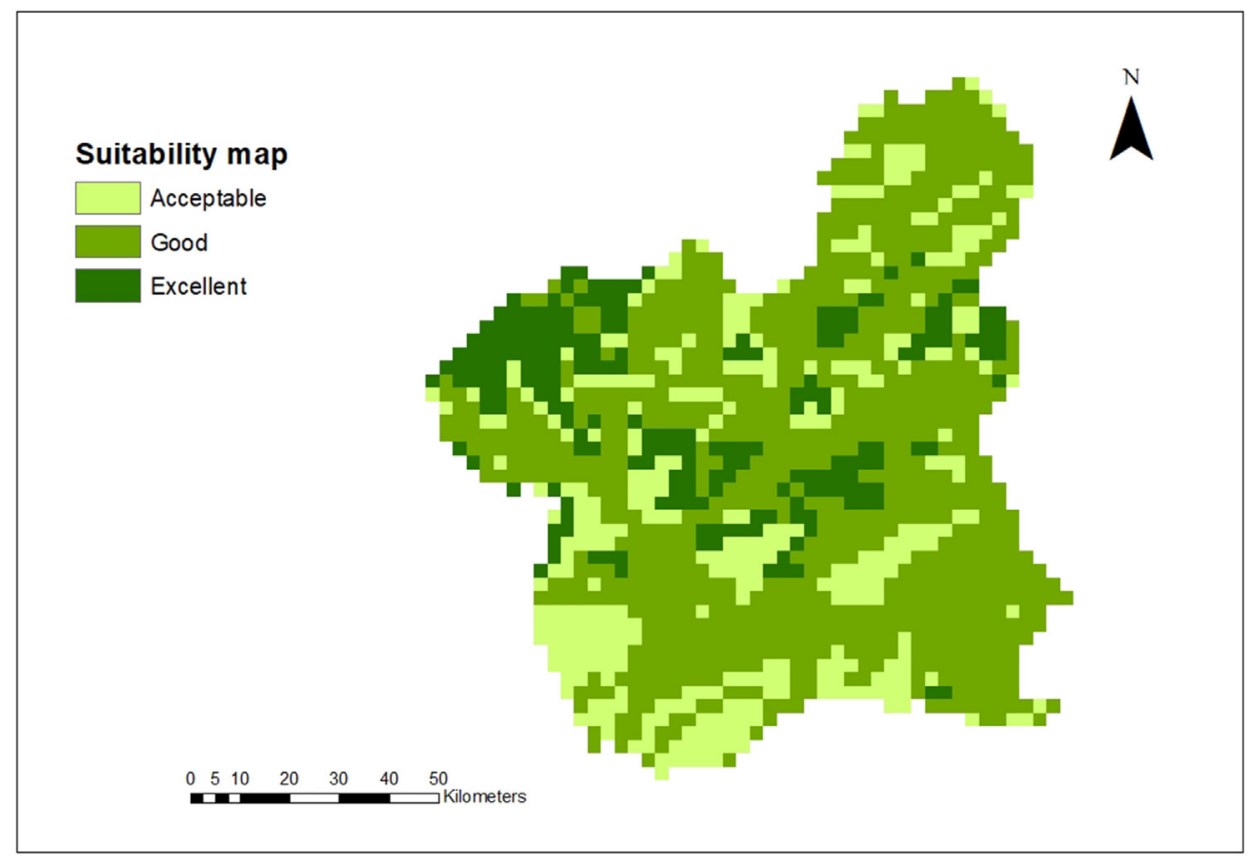

Fig. 12. Suitability map of Murcia region. Example of applying MCDM methods in combination with GIS.

optimal placement for certain technologies [56]. For this work, as SGE could be exploited almost everywhere, is the suitability level of exploiting SGE by GHSP in a certain area, rather than the optimal placement, the goal that could be reached. To demonstrate what can be done in this regard, a basic example is described here. For this example, every indicator map is a criteria layer used in the MCDM.

The criteria are weighted, according to the understanding of hypothetical experts, based on their influence to determine the areas where GSHP will perform with the best results. In order to be able to compare one criterion to each other, a normalization of the data was carried out where quantitative data were also translated into qualitative. In this process, each criteria value was first categorized into three groups according to their suitability to reach the goal and a score was assigned to the categories: 1 is for the category considered acceptable, 2 is good, and 3 is excellent. Secondly, the weighted sum in GIS was made according to (1) using the "map algebra" function. We assumed that $\left(w_{1}, w_{2}, w_{3}, w_{4}, w_{5}\right.$ and $\left.w_{6}\right)$ are the weights and $\left(S_{1}, S_{2}, S_{3}, S_{4}, S_{5}\right.$ and $\left.S_{6}\right)$ are the scores previously assigned (Table 6). Fig. 11 shows the visualization of thematic maps and the values of a given point. The outcome is a map (Fig. 12) where suitability of the GSHP to perform with the best results in every pixel of the map can be checked. This tool may be of great help for energy decision makers and District Heating and Cooling projects promoters, among others.

Weighted sum $=\left(w_{1}\right.$

$\left.* S_{1}\right)+\left(w_{2} * S_{2}\right)+\left(w_{3} * S_{3}\right)+\left(w_{4} * S_{4}\right)+\left(w_{5} * S_{5}\right)+\left(w_{6} * S_{6}\right)$

(1).

\section{Discussion and conclusions}

The results show how the principal indicators governing the suitability of exploiting shallow geothermal energy potential across Europe vary in space and how they link with population. This panEuropean assessment aims to give guidance on which indicators are most important for the exploitation of SGE in Europe. This analysis is not intended for calculating exact site-specific values, at a local scale. For local assessments of SGE suitability, more detailed spatial datasets are required, possibly complemented with local measurements. For example, the approach does not take hydrogeological conditions into account because data at the European level are not comparable for this purpose, while for a local assessment, hydrogeological data, including protected zones, typically are available and should be considered.

The thematic maps and statistics, based on geological, climatic, and environmental factors were composed and constructed of freely available datasets and information. The combination between area and population spatial assessment showed the most frequent indicator values in the study area and identified those ranges where population is concentrated. This can offer support in finding hot spots for the exploitation of shallow geothermal energy.

More specifically, from the results, the following can be concluded. The geology factors that were derived show that practically the whole population lives in areas with thermal conductivity values between 1.2 and $3 \mathrm{~W} / \mathrm{mK}$. Thus, scientific research and technological innovation must focus on this range. The application of borehole heat exchangers and grouting for these specific thermal conductivity values is likely to contribute to the improvement of the overall performance of the system and reduce installation and associated costs, and allow for a targeted promotion of the use of these systems. Higher thermal conductivity values were also found, but little population was associated with these areas and thus there is not much need for efforts in these areas.

From the geology it can be also concluded that while unconsolidated materials dominate the area, more than half of the population is located in consolidated materials areas. In these areas, down-hole hammer is considered the most appropriate drilling technique, with the associated cost. Thus, to reduce the upfront costs of SGEs, the reduction cost of drilling in consolidated materials must be pursued.

From the climatic factors it is shown that most of the population lives in areas with a mean annual temperature between 5 and $21^{\circ} \mathrm{C}$ and little population was found in areas with temperatures below $0{ }^{\circ} \mathrm{C}$. Air temperature amplitude also shows that one quarter of the population (125 million people) lives in areas where the use of 
GSHP to provide space heating and cooling is considered the most suitable technology compared to air heat pumps. Another quarter lives in areas where GSHP would likely be the most suitable one depending on site-specific distance to the sea.

Air temperature also shows a clear tendency for the population to concentrate in areas of low to medium energy needs, with no severe climatic conditions based on heating and cooling degree days, and areas with high values of HDD + CDD account for a small share of the population.

From the environmental protection point of view, it can be highlighted that a large $85 \%$ of the territory does not show, in principle, any kind of restriction on the exploitation of the shallow geothermal resource. However, for the rest of the territory, GSHP could entail complicated bureaucratic processes that could result in increased cost for the installation or even in denial of permission. Only $0.08 \%$ of the area percentage is directly protected and no human activity is allowed.

As aforementioned, MCDM can be used as input into a MultiCriteria Decision-Making (MCDM) framework. When applying a MCDM framework to the regional level, as for the example presented in southeastern Spain, other relevant physical layers can be also included, that are not available at the European level. An important one is for example the presence of groundwater and areas of groundwater protection. From this, detailed suitability maps can be generated which regional policymakers can use to identify areas where investments in the related technologies are likely to be most effective. From the example for southeastern Spain it can be concluded that the spatial information can also be used to identify non-exploited areas where physical indicators show that conditions for SGE are favorable, and to point out gaps in legislation and awareness.

At the European level, maps can be used for the creation of a shallow geothermal suitability map, previously done by Ref. [29]. For this purpose, several data adjustments would be needed such as the conversion of quantitative into qualitative data, among others.

The approach adopted here is applicable to other territories for large-scale regional assessments. Continental scale information, as use and provided in this work, is quite helpful to the scientific community and decision makers.

\section{CRediT authorship contribution statement}

Adela Ramos-Escudero: Visualization, Software, Writing original draft. M. Socorro García-Cascales: Resources, Data curation, Supervision. Jose M. Cuevas: Methodology, Investigation, Writing - review \& editing. Burkhard Sanner: Investigation, Validation, Writing - review \& editing. Javier F. Urchueguía: Conceptualization, Validation, Writing - review \& editing.

\section{Declaration of competing interest}

The authors declare that they have no known competing financial interests or personal relationships that could have appeared to influence the work reported in this paper.

\section{Acknowledgements}

This article is part of a project that has received funding from the European Union's Horizon 2020 research and innovation programme under grant agreement No 727583 (GEOCOND).

This work was partially supported by the Spanish Ministry of Economy and Competitiveness (MINECO), reference TIN2017-86647-P. The authors also acknowledge the support of the Fundación Séneca (Region of Murcia, Spain through the Grant 19882-GERM-15.

\section{References}

[1] European Commission, COM, 2020 final Communication from the Commission Europe 2020. A strategy for smart, sustainable and inclusive growth, (2010). https://eur-lex.europa.eu/legal-content/EN/TXT/PDF/?uri=CELEX: 52010DC2020\&from=en, 2010.

[2] European Commission, Roadmap 2050 Low Carbon Europe, 2012, pp. 1-9, https://doi.org/10.2833/10759.

[3] European Commission, Progress made in cutting emissions. https://ec.europa. eu/clima/policies/strategies/progress_en, 2019.

[4] European Commission, Energy efficiency plan, 0109:FIN: EN:PDF, https://eurlex.europa.eu/LexUriServ/LexUriServ.do?uri=COM:2011, 2011, 2011.

[5] European Commission, Heating and cooling. Comprehensive assessment. https://ec.europa.eu/energy/en/topics/energy-efficiency/heating-and-cooling, 2019.

[6] D.Ü.-V. Oswaldo Lucon, Lead, mitigation of climate change. Contribution of working group III to the fifth assessment report of the intergovernmental panel on climate change in buildings. http://swcarr.arizona.edu/sites/default/ files/ACCSWUS_Ch2.pdf, 2013.

[7] European Council, Directive (EU) 2018/2001 of the European Parliament and of the CouncilL of 11 December 2018 on the promotion of the use of energy from renewable sources (recast), Off. J. Eur. Union 2018 (2018). https://eurlex.europa.eu/eli/dir/2018/2001/oj.

[8] B. Sanner, Summary of EGC 2019 country update reports on geothermal energy in Europe, eur. Geotherm. Congr. 2019, 199818 (2019). http:// europeangeothermalcongress.eu/wp-content/uploads/2019/07/CUR-00Summary-Europe.pdf.

[9] B. Sigfússon, A. Uihlein, 2015 JRC Geothermal Energy Status Report, 2015, https://doi.org/10.2790/959587. European Commission - Joint Research Centre.

[10] EGEC, Strengthening shallow geothermal energy for a clean heating and cooling supply in Europe!. https://www.egec.org/strengthening-shallowgeothermal-energy-for-a-clean-heating-and-cooling-supply-in-europe/, 2019.

[11] B. Sanner, C. Karytsas, Current status of ground source heat pumps and underground thermal energy storage in Europe 32 (2003) 579-588, https:// doi.org/10.1016/S0375-6505(03)00060-9.

[12] G.I.A. Space, Comparison of NSGE installations in the Alpine region selected for reproducibility and transferability relevance. https://www.alpine-space. eu/projects/greta/en/project-results/results-by-workpackage/wp2regulations, 2015.

[13] B.M.S. Giambastiani, F. Tinti, D. Mendrinos, M. Mastrocicco, Energy performance strategies for the large scale introduction of geothermal energy in residential and industrial buildings: the GEO.POWER project,, Energy Pol. 65 (2014) 315-322, https://doi.org/10.1016/j.enpol.2013.10.008.

[14] A. García-Gil, E. Vázquez-Suñé, J.Á. Sánchez-Navarro, J. Mateo Lázaro, Recovery of energetically overexploited urban aquifers using surface water, J. Hydrol 531 (2015) 602-611, https://doi.org/10.1016/j.jhydrol.2015.10.067.

[15] K.P. Tsagarakis, L. Efthymiou, A. Michopoulos, A. Mavragani, A.S. Anđelković, F. Antolini, M. Bacic, D. Bajare, M. Baralis, W. Bogusz, S. Burlon, J. Figueira, M.S. Genç, S. Javed, A. Jurelionis, K. Koca, G. Ryżyński, J.F. Urchueguia, B. Žlender, A review of the legal framework in shallow geothermal energy in selected European countries: need for guidelines, Renew, Energy (2018), https://doi.org/10.1016/j.renene.2018.10.007.

[16] S. Haehnlein, P. Bayer, P. Blum, International legal status of the use of shallow geothermal energy, Renew. Sustain. Energy Rev. 14 (2010) 2611-2625, https://doi.org/10.1016/j.rser.2010.07.069.

[17] V. Somogyi, V. Sebestyén, G. Nagy, Scientific achievements and regulation of shallow geothermal systems in six European countries - a review, Renew. Sustain. Energy Rev. 68 (2017) 934-952, https://doi.org/10.1016/ j.rser.2016.02.014.

[18] Á. Ragnarsson, Í. Geosurvey, Geothermal energy use, country update for Iceland, Eur. Geotherm. Congr 2013 (2013) 1-11. https://www.geothermalenergy.org/pdf/IGAstandard/EGC/2013/EGC2013_CUR-16.pdf.

[19] R. Goodman, G.L. Jones, J.G. Kelly, Methodology in assessment and presentation of low enthalpy geothermal resources in, proc. World geotherm, Congr 2010 (2010) 25-29.

[20] International Energy Agency, Transition to sustainable buildings. Strategies and opportunities to 2050. https://doi.org/10.1787/9789264202955-en, 2013.

[21] C. and D. Directorate general European programmes, EUROPE 2020 Cyprus national reform programme 2019 republic of Cyprus. https://ec.europa.eu/ info/sites/info/files/2019-european-semester-national-reform-programmecyprus-en.pdf, 2019.

[22] A. Gemelli, A. Mancini Adriano, S. Longhi, GIS-based energy-economic model of low temperature geothermal resources: a case study in the Italian Marche region, Renew, Energy 36 (2011) 2474-2483, https://doi.org/10.1016/ j.renene.2011.02.014.

[23] K. Schiel, O. Baume, G. Caruso, U. Leopold, GIS-based modelling of shallow geothermal energy potential for CO2emission mitigation in urban areas, Renew. Energy 86 (2016) 1023-1036, https://doi.org/10.1016/j.renene. 2015.09.017.

[24] J. Ondreka, M.I. Rüsgen, I. Stober, K. Czurda, GIS-supported mapping of shallow geothermal potential of representative areas in south-western Germany-Possibilities and limitations, Renew. Energy 32 (2007) 2186-2200, 
https://doi.org/10.1016/j.renene.2006.11.009.

[25] A. Casasso, R. Sethi, G.POT: a quantitative method for the assessment and mapping of the shallow geothermal potential,, Energy 106 (2016) 765-773, https://doi.org/10.1016/j.energy.2016.03.091.

[26] Y. Zhang, R. Choudhary, K. Soga, Influence of GSHP system design parameters on the geothermal application capacity and electricity consumption at cityscale for Westminster, Energy Build. 106 (2015) 3-12, https://doi.org/ 10.1016/j.enbuild.2015.07.065. London.

[27] M. Alcaraz, A. García-Gil, E. Vázquez-Suñé, V. Velasco, Advection and dispersion heat transport mechanisms in the quantification of shallow geothermal resources and associated environmental impacts, Sci. Total Environ. 543 (2016) 536-546, https://doi.org/10.1016/j.scitotenv.2015.11.022.

[28] A. Casasso, S. Pestotnik, D. Rajver, J. Jež, J. Prestor, R. Sethi, Assessment and mapping of the closed-loop shallow geothermal potential in Cerkno (Slovenia), Energy Procedia 125 (2017) 335-344, https://doi.org/10.1016/ j.egypro.2017.08.210.

[29] F. Tinti, S. Kasmaee, M. Elkarmoty, S. Bonduà, V. Bortolotti, Suitability evaluation of specific shallow geothermal technologies using a GIS-Based multi criteria decision analysis implementing the analytic hierarchic process, Energies 11 (2018), https://doi.org/10.3390/en11020457.

[30] T.V. Ramachandra, B.V. Shruthi, Spatial mapping of renewable energy potential, Renew. Sustain. Energy Rev. 11 (2007) 1460-1480, https://doi.org/ 10.1016/j.rser.2005.12.002.

[31] Institut Cartogràfic i Geològic de Catalunya, Legend of Geoindex viewer Shallow geothermal potential. https://www.icgc.cat/en/Public-Adminis tration-and-Enterprises/Tools/Geoindex-viewers/Geoindex-Shallowgeothermal-energy, 2018.

[32] G.I.S. GeoDH, Viewer. Mining and geological survey of Hungary. https://map. mbfsz.gov.hu/geo_DH/, 2015.

[33] M.S. Arvanitis, D. Kanaris, P. Krassakis, Thermomap Viewer. https://www. thermomap.eu/, 2014.

[34] Rijkdienst voor Ondernemend Nederland, WKOTool, Ontdek de mogelijkheden van bodemenergie. https://wkotool.nl/, 2015.

[35] A. García-Gil, E. Vázquez-Suñe, M.M. Alcaraz, A.S. Juan, J.Á. Sánchez-Navarro, M. Montlleó, G. Rodríguez, J. Lao, GIS-supported mapping of low-temperature geothermal potential taking groundwater flow into account, Renew. Energy 77 (2015) 268-278, https://doi.org/10.1016/j.renene.2014.11.096.

[36] J. Li, Y. Zhang, GIS-supported certainty factor (CF) models for assessment of geothermal potential: a case study of Tengchong County, southwest China," Energy 140 (2017) 552-565, https://doi.org/10.1016/j.energy.2017.09.012.

[37] D. Bertermann, H. Klug, L. Morper-Busch, A pan-European planning basis for estimating the very shallow geothermal energy potentials, Renew. Energy (2015), https://doi.org/10.1016/j.renene.2014.09.033.

[38] EGDI. European Geological Data Infraestructure. EuroGeoSurveys European Geoscience for Society., Hydrogeological Map of Europe, (n.d.). http:// www.europe-geology.eu/groundwater/groundwater-map/hydrogeologicalmap-of-europe/.

[39] A. Galgaro, E.D.I. Sipio, A. Ramos-Escudero, J.M. Cuevas, D. Righini, R. Pasquali, J. Vercruysse, D. Bertermann, L. Pockele, European drillability mapping for shallow geothermal applications, EGU gen. Assem. 2020 (2020), 792355, https://doi.org/10.5194/egusphere-egu2020-8584.
[40] S.E. Fick, R.J. Hijmans, WorldClim Version2 | WorldClim - Global Climate Data. http://worldclim.org/, 2017.

[41] EUROSTAT, Cooling and heating degree days by country - annual data. https:// ec.europa.eu/eurostat/web/products-datasets/product? code=nrg_chdd_a, 2018.

[42] EUROSTAT, Energy statistics - cooling and heating degree days, n.d. https://ec. europa.eu/eurostat/cache/metadata/en/nrg_chdd_esms.htm.

[43] U.S. Geological Survey's Center for Earth Resources Observation and Science (EROS), 30 Arc-Second DEM of Europe, 1996 arc-second DEM of Europe, https://databasin.org/search/\#query=30.

[44] E. European environmental agency, nationally designated areas (CDDA). https://www.eea.europa.eu/data-and-maps/data/nationally-designatedareas-national-cdda-14\#tab-metadata, 2019.

[45] Nigel Dudley, Guidelines for applying protected area management categories. https://doi.org/10.2305/iucn.ch.2008.paps.2.en, 2008.

[46] N.N.S.D. and A.C. (SEDAC). Center for International Earth Science Information Network - CIESIN - Columbia University, and Centro Internacional de Agricultura Tropical - CIAT. 2005. Gridded Population of the World, 2005, https:// doi.org/10.7927/H4XK8CG2. Version 3 (GPWv3): Population Density Grid. Palisades, Gridded Population of the World, Version 3 (GPWv3): Population Density Grid.

[47] VDI 4640 blatt 1 berichtigung:2011-12. https://www.vdi.de, 2011.

[48] L. Rybach, Design and performance of borehole heat exchanger/heat pump systems by Ladislaus RYBACH. https://doi.org/10.1016/j.egypro.2015.11.078, 2000, 173-181.

[49] B. Sigfusson, A. Uihlein, Geothermal energy status report - JRC science and policy reports. https://doi.org/10.2790/460251, 2015.

[50] S. Signorelli, T. Kohl, Regional ground surface temperature mapping from meteorological data, Glob. Planet. Change 40 (2004) 267-284, https://doi.org/ 10.1016/j.gloplacha.2003.08.003.

[51] P.F. Healy, V.I. Ugursal, Performance and economic feasibility of ground source heat pumps in cold climate, Int. J. Energy Res. 21 (1997) 857-870, https:// doi.org/10.1002/(sici)1099-114x(199708, 21:10<857::aid-er279>3.3.co;2-t.

[52] M. De Carli, A. Bernardi, M. Cultrera, G. Dalla, S. Id, A. Di, B. Id, G. Emmi, A. Galgaro, S. Graci, D. Mendrinos, G. Mezzasalma, R. Pasquali, S. Pera, R.P. Id, A. Zarrella, A database for climatic conditions around Europe for promoting GSHP solutions. https://doi.org/10.3390/geosciences8020071, 2018, 1-19.

[53] Environmental Systems Research Institute, ESRI, 2011. ArcGIS desktop: release 10, 2011.

[54] C. Energía y Minas de la Región de Murcia, Plan Energético de la Región de Murcia 2016-2020, 2016.

[55] D.G. Industria Energía y Minas de la Región de Murcia, Las Energías Renovables. Energía Geotérmica., 2015. https://www.museosregiondemurcia.es/ documents/4106806/4419780/Cap\&iacute;tulo-06-8-Geot\&eacute;rmicaPIAEERM.pdf/752420f9-9a8b-4849-b02f-286ded4964f1.

[56] J.M. Sánchez-Lozano, J. Teruel-Solano, P.L. Soto-Elvira, M. Socorro GarcíaCascales, Geographical Information Systems (GIS) and Multi-Criteria Decision Making (MCDM) methods for the evaluation of solar farms locations: case study in south-eastern Spain, Renew. Sustain. Energy Rev. 24 (2013) 544-556, https://doi.org/10.1016/j.rser.2013.03.019. 